\title{
Editorial: special issue on regime shifts and tipping points in ecology
}

\author{
V. Dakos • A. Hastings
}

It is an old idea in ecology that environmental change can induce rapid transformations at times impossible to reverse. Early manipulation experiments hinted that coastal communities could organize into different distinct configurations after a disturbance (Dayton 1971). Along these lines, a theory of multiple stable states had been developed (Holling 1973; Lewontin 1969) to explain patterns in coral reefs, semiarid ecosystems, shallow lakes, or fisheries (Scheffer et al. 2001), even if experimental evidence for alternative states has been debated (Schroder et al. 2005). Nonetheless, the intuition behind the possibility of shifting between alternative attractors at the cost of small interventions (aka small events can have big consequences) has precipitated from ecology, to the study of climatic events, social transformations, and even to the way of understanding banking systems. These ideas have led to lively discussions about the possible existence of tipping points at which ecological systems may "fall off" to a different regime that may be difficult to escape.

Current high rates of extinction events, rapid environmental changes, high desertification risks, a potential for climatic shifts, and even financial collapses have also made critical transitions of high interest. Suggestions have been made that even the entire biosphere may be approaching a critical transition (Barnosky et al. 2012). Therefore, being able to quantify the resilience of ecological systems (i.e., the amount of disturbance ecosystems can undertake before shifting to alternative state) can be a promising management strategy

\footnotetext{
V. Dakos

Integrative Ecology Group, Estación Biológica de Doñana, c/ Américo Vespucio s/n, 41092 Sevilla, Spain

e-mail: vasilis.dakos@ebd.csic.es

A. Hastings $(\bowtie)$

Department of Environmental Science and Policy, University of California, Davis, CA 95616, USA

e-mail: amhastings@ucdavis.edu
}

for avoiding abrupt unexpected transitions. However, our ability to quantify ecological resilience is still questionable.

In the last 5 years, theory has suggested that we may be able to derive early warning signals derived from time series in systems that are about to experience a critical transition (Scheffer et al. 2009, www.early-warning-signals.org). Most of these ideas are reinterpretations of well-understood dynamical properties that unfold close to bifurcation points. But the fresh innovative features have created momentum for developing new methods and for studying a broader range of tipping points both in theory and practice.

In this issue of Theoretical Ecology, we focus on this emerging field of critical transitions with an emphasis on measuring the resilience of ecological systems and the possibility of anticipating critical transitions. Boettiger et al. (2013) classify the so far work on early warnings and identify uncharted grounds in the study of critical transitions. Part of the uncharted grounds is covered by exploring how time delays between drivers and environmental variables affect the behavior of early warnings (D'Odorico et al. 2013; Guttal et al. 2013), how transitions from cyclic to noncyclic regimes and vice versa can be anticipated (Batt et al. 2013), and how traveling waves may start propagate and can be detected to signal the expansion of invasion fronts (Kuehn 2013). These studies shed light on aspects widely encountered in real ecosystems that hinder or completely cancel our ability to identify any approaching transitions. Another potential signal is flickering, the occasional excursion of an ecosystem between alternative states, which is probably most frequently encountered under natural perturbation regimes. Dakos et al. (2013) show that, under flickering, early warnings are to be interpreted with caution, while other indicators may serve as better signals. But still, the work on critical transitions and their precursors is at its infancy. Is there a potential for using these approaches in more complex cases? Hefley et al. (2013) further develop state approaches to detect early warning signs for shifts and demonstrate their utility in a specific system of 
declining populations of bobwhite quail that could be facing extinction. O'Regan and Drake (2013) show theoretically how we may have more chances to detect the elimination of disease epidemics rather their emergence. In a completely different context, Lade et al. (2013) demonstrate the possibility of triggering a critical transition in an ecosystem by the social dynamics played out between members of a community and suggest how such transition may be possible to detect. Despite the increasing number of successful experiments (Dai et al. 2012), such theoretical expectations are still difficult to apply when managing real-world situations. Even in the presence of adequate data and multiple numerical experiments from high complex climate models, tipping point detection is challenging as shown from analysis of the Amazon forest dieback (Boulton et al. 2013). Thus, new alternative ways of data analysis are required, like reconstructing attractors from a whole lake experiment (Seekell et al. 2013).

Whether approaches for detecting or predicting critical transitions will be possible to apply for real time management and decision making is still hard to say. Nevertheless, the ubiquity of critical transitions and their real importance across many systems and disciplines makes their exploration both timely and necessary. The papers in this issue both provide a summary of the current state of the field and indicate many avenues for future exploration.

\section{References}

Barnosky AD, Hadly EA, Bascompte J, Berlow EL, Brown JH, Fortelius M, Getz WM, Harte J, Hastings A, Marquet PA, Martinez ND, Mooers A, Roopnarine P, Vermeij G, Williams JW, Gillespie R, Kitzes J, Marshall C, Matzke N, Mindell DP, Revilla E, Smith AB (2012) Approaching a state shift in earth's biosphere. Nature 486:52-58

Batt RD, Brock WA, Carpenter SR, Cole JJ, Pace ML, Seekell DA (2013) Asymmetric response of early warning indicators of phytoplankton transitions to and from cycles. Theor Ecol (this issue). doi:10.1007/s12080-013-0190-8
Boettiger C, Ross N, Hastings A (2013) Early warning signals: the charted and uncharted territories. Theor Ecol (this issue). doi:10. 1007/s12080-013-0192-6

Boulton CA, Good P, Lenton TM (2013) Early warning signals of simulated Amazon rainforest dieback. Theor Ecol (this issue). doi:10.1007/s12080-013-0191-7

Dai L, Vorselen D, Korolev KS, Gore J (2012) Generic indicators for loss of resilience before a tipping point leading to population collapse. Science 336:1175-1177. doi:10.1126/science.1219805

Dakos V, van Nes EH, Scheffer M (2013) Flickering as an early warning signal. Theor Ecol (this issue). doi:10.1007/s12080-013-0186-4

Dayton PK (1971) Competition, disturbance, and community organization: the provision and subsequent utilization of space in a rocky intertidal community. Ecol Monogr 41:351-389

D'Odorico P, Ridolfi L, Laio F (2013) Precursors of state transitions in stochastic systems with delay. Theor Ecol (this issue). doi:10.1007/ s12080-013-0188-2

Guttal V, Jayaprakash C, Tabbaa OP (2013) Robustness of early warning signals of regime shifts in time-delayed ecological models. Theor Ecol (this issue). doi:10.1007/s12080-013-0194-4

Hefley T, Tyre A, Blankenship E (2013) Statistical indicators and statespace population models predict extinction in a population of bobwhite quail. Theor Ecol (this issue). doi:10.1007/s12080013-0195-3

Holling CS (1973) Resilience and stability of ecological systems. Annu Rev Ecol Syst 4:1-23

Kuehn C (2013) Warning signs for wave speed transitions of noisy Fisher-KPP invasion fronts. Theor Ecol (this issue). doi:10.1007/ s12080-013-0189-1

Lade SJ, Tavoni A, Levin SA, Schlüter M (2013) Regime shifts in a social ecological system. Theor Ecol (this issue). doi:10.1007/ s12080-013-0187-3

Lewontin RC (1969) The meaning of stability. In: Woodwell GM, Smith HH (eds) Diversity and stability in ecological systems: report of a symposium held May 26-28. Biology Department, Brookhaven National Laboratory, Upton, New York. pp. 13-24

O'Regan SM, Drake JM (2013) Theory of early warning signals of disease emergence and leading indicators of elimination. Theor Ecol (this issue). doi:10.1007/s12080-013-0185-5

Scheffer M, Bascompte J, Brock WA et al (2009) Early-warning signals for critical transitions. Nature 461:53-59. doi:10.1038/nature08227

Scheffer M, Carpenter S, Foley JA et al (2001) Catastrophic shifts in ecosystems. Nature 413:591-596

Schroder A, Persson L, De Roos AM (2005) Direct experimental evidence for alternative stable states: a review. Oikos 110:3-19

Seekell DA, Cline TJ, Carpenter SR, Pace ML (2013) Evidence of alternate attractors from a whole-ecosystem regime shift experiment. Theor Ecol (this issue). doi:10.1007/s12080-013-0183-7 